\title{
The Three Types of Factor Models: A Comparison of Their Explanatory Power
}

\section{Gregory Connor}

\begin{abstract}
Multifactor models of security market returns can be divided into three types: macroeconomic, fundamental, and statistical factor models. Macroeconomic factor models use observable economic time series, such as inflation and interest rates, as measures of the pervasive shocks to security returns. Fundamental factor models use the returns to portfolios associated with observed security attributes such as dividend yield, the book-to-market ratio, and industry identifiers. Statistical factor models derive their pervasive factors from factor analysis of the panel data set of security returns. This paper compares the explanatory power of these three approaches for U.S. equity returns.
\end{abstract}

W ith some blurring at the boundaries, multifactor models of asset returns can be divided into three types: macroeconomic, statistical, and fundamental. Our empirical findings confirm the conventional wisdom that statistical factor models and fundamental factor models outperform macroeconomic factor models in terms of explanatory power. The findings also indicate that the fundamental factor model slightly outperforms the statistical factor model. This result is at first surprising, because statistical factor models are estimated by maximizing explanatory power. So, how can an alternative outperform them by this criterion? The explanation lies in the much larger number of external data sources used in fundamental factor models, particularly the large set of industry dummies. Another empirical finding is that the marginal explanatory power of a macroeconomic factor model is zero when it is added to the fundamental factor model. This result may indicate that the fundamental factors (in some unknown combination) capture the same risk characteristics as the macroeconomic factors.

\section{TYPES OF FACTOR MODELS}

Macroeconomic factor models are the simplest and most intuitive type. They use observable economic time series as measures of the pervasive factors in security returns. ${ }^{1}$ Some of the macroeconomic variables typically used as factors are inflation, the

Gregory Connor is director of research, Europe, for BARRA International. percentage change in industrial production, the excess return to long-term government bonds, and the realized return premium of low-grade corporate bonds relative to high-grade bonds. The random return of each security is assumed to respond linearly to the macroeconomic shocks. As in all factor models, each security also has an assetspecific return unrelated to the factors. A security's linear sensitivities to the factors are called the factor betas of the security. A drawback to macroeconomic factor models is that they require identification and measurement of all the pervasive shocks affecting security returns. A small number of pervasive sources of risk may exist, but without knowing exactly what they are, or lacking data to measure them, they are of little use in explaining returns.

Statistical factor models use various maximumlikelihood and principal-components-based factor analysis procedures on cross-sectional/time-series samples of security returns to identify the pervasive factors in returns.

Macroeconomic and statistical factor models both estimate a firm's factor beta by time-series regression. Given the nature of security returns data, this limitation is substantial. Time-series regression requires a long and stable history of returns for a security to estimate the factor betas accurately.

Fundamental factor models do not require timeseries regression. They rely on the empirical finding that company attributes such as firm size, dividend yield, book-to-market ratio, and industry 
classification explain a substantial proportion of common return. A fundamental factor model uses observed company attributes as factor betas. The factors in a fundamental factor model are the realized returns to a set of mimicking portfolios designed to capture the marginal returns associated with a unit of exposure to each attribute. For example, the dividend yield factor is the realized return per extra unit of dividend yield, holding other attributes constant. In the case of a fundamental factor model, the factor betas are exogenously determined, firm-specific attributes rather than estimated sensitivities to random factors, and the factor returns are empirically determined random returns associated with these various attributes. $^{2}$

The relationship among the three types of models, outlined in Table 1, can be described in terms of inputs, estimation technique, and outputs. In all cases, factor model estimation involves time-series regression or cross-sectional regression or both. Some statistical factor models rely on nonlinear maximum-likelihood theory for their derivation, but the implementation of the nonlinear maximum-likelihood procedure is usually done through a recursive series of repeated cross-sectional/time-series regressions. ${ }^{3}$

The three types of factor models are not necessarily inconsistent. In the absence of estimation error and with no limits on data availability, the three models are simply restatements or (to use a technical term from factor modeling) rotations of one another. In this eclectic view of the world, the three factor models are not in conflict and all can hold simultaneously.

In a macroeconomic factor model, the factors are defined by economic theory and observed externally to the security returns data. In a statistical factor model, the factors are estimated from the sample returns data by maximizing the fit of the model. Statistical factors, because they are essentially unlabeled statistical artifacts, can be recombined linearly without altering the model. Recombining a set of statistical factors linearly produces an alternative set of statistical factors, equally valid, or a rotation of the original set. Suppose that both factor models are true-that is, the macroeconomic factors capture all the pervasive movements in security returns and the statistical factors and the macroeconomic factors both are measured without error. In this case, the two factor representations will differ only by a rotation and the statistical factors can be linearly recombined to be made identical to the macroeconomic factors.

A fundamental factor model and the other two types are not theoretically inconsistent. Suppose that a fundamental factor model correctly captures the individual assets' sensitivities to the pervasive risks in the economy, and suppose that a macroeconomic model also correctly captures the pervasive sources of risk. Then, the firm-specific attributes used in a fundamental factor model could be combined to produce the factor betas from the macroeconomic factor model. For example, a typical macroeconomic factor is term structure risk (often measured by the realized monthly return on a long-term government bond portfolio minus the short-term government bond return). The sensitivity of a security's return to this factor is the security's term structure beta. Two typical fundamental risk attributes are firm leverage and dividend yield. So, for example, perhaps each security's dividend yield and firm leverage attributes could be linearly recombined to equal its term structure beta. This again is a type of rotation, because the attributes in the fundamental factor model can be linearly recombined to equal the factor betas in the macroeconomic factor model.

\section{EXPLANATORY POWER AS A DESCRIPTIVE STATSTIC}

The theoretical consistency among the three types of models requires more emphasis on empirical work to choose among them. In a recent paper, Connor and Korajczyk proposed a test for determining the number of statistical factors in security returns. ${ }^{4}$ The intuition for the test is straightforward. Suppose that one wishes to test whether

Table 1. An Overview of the Empirical Procedures For the Three Types of Factor Models

\begin{tabular}{llll}
\hline Factor Model Type & \multicolumn{1}{c}{ Inputs } & Estimation Technique & Outputs \\
\hline Macroeconomic & $\begin{array}{c}\text { Security returns and macroeconomic } \\
\text { variables } \\
\text { Statistical }\end{array}$ & Time-series regression & Security factor betas \\
Fundamental & $\begin{array}{c}\text { Security returns and security } \\
\text { characteristics }\end{array}$ & $\begin{array}{c}\text { Iterated time-series/cross- } \\
\text { sectional regression } \\
\text { Cross-sectional } \\
\text { regression }\end{array}$ & $\begin{array}{c}\text { Statistical factors and security } \\
\text { factor betas } \\
\text { Fundamental factors }\end{array}$ \\
\hline
\end{tabular}


five factors are sufficient to explain all the pervasive movements in security returns. Connor and Korajczyk suggested estimating both a five-factor model and a six-factor model on the same data set. Their test relies on the difference in the crosssectional average of asset-specific variances between the two models. If five factors are enough, then this difference should be near zero because the sixth factor should have negligible explanatory power. The reason is that under the hypothesis of five factors, the sixth factor is a "pseudofactor." It can explain some of the asset-specific variance for a few securities, but its average explanatory power across all the securities must be close to zero. If six factors are necessary, then the difference in the average asset-specific variance should be strictly positive because the sixth factor is a true factor and therefore has pervasive influence in the crosssection of assets. The increase in explanatory power from adding a factor is the basis for the test of whether the additional factor is needed.

Let $\sigma_{i}$ denote the total return variance of security $i$ and $\sigma_{\epsilon i}$ denote the asset-specific return variance (the part of $i$ 's total variance that is not explained by the factors). Let $\sigma$ and $\sigma_{\epsilon}$ denote the averages of $\sigma_{i}$ and $\sigma_{e i}$, respectively, across all the securities. Define the explanatory power of a factor model as 1 minus the average asset-specific variance divided by the average total variance (explanatory power $\left.=1-\sigma_{\epsilon} / \sigma\right)$. The explanatory power of each individual factor in the factor model is the change in the explanatory power of the model when the factor is added to it.

Table 2 shows the results from applying this test to a statistical factor model estimated on U.S. returns data over the 108-month period from January 1985 through December 1993 for 779 highcapitalization U.S. equities. ${ }^{5}$ This table reproduces one of the results of Connor and Korajczyk using a somewhat different sample. ${ }^{6}$ Connor and Korajczyk mentioned that their measure for explanatory power is applicable to the types of factor models
Table 2. Explanatory Power of Five Statistical Factors

\begin{tabular}{cc}
\hline Factor & $\begin{array}{c}\text { Increase in Explanatory } \\
\text { Power from Adding Each Factor }\end{array}$ \\
\hline 1 & $29.0 \%$ \\
2 & 3.5 \\
3 & 3.1 \\
4 & 1.8 \\
5 & 1.7 \\
All factors & 39.0 \\
\hline
\end{tabular}

other than statistical factor models. The methodology can be used to test whether a proposed macroeconomic factor or fundamental factor has a pervasive influence (and so is a true factor) or has only limited explanatory power (and so is a pseudofactor).

Table 3 shows the same statistic applied to a macroeconomic factor model with five chosen factors (inflation, term structure, industrial production, junk-bond premium, and unemployment) estimated on the same sample. ${ }^{7}$ In the first column, as in Table 2, the explanatory power statistic is applied with each macroeconomic factor in turn used as the fifth factor. Note that both the lowgrade bond premium and the term structure premium must be included to get a reasonable fit in the model. If either of those two variables is dropped, the fit of the model falls dramatically. None of the other variables contributes much to the explanatory power of the model.

Because macroeconomic factors are not ordered, each can be treated as the first factor, and its explanatory power when used alone can also be measured, as in the right-hand column of Table 3. Inflation, which has almost no marginal explanatory power, given the other four variables, does have some explanatory power when used alone. ${ }^{8}$

Table 4 applies the test to a fundamental factor model using a set of BARRA fundamental factors consisting of 55 industry dummies plus 12 risk

Table 3. The Explanatory Power of the Macroeconomic Factors

\begin{tabular}{lcc}
\hline Factor & $\begin{array}{c}\text { Explanatory Power from Using } \\
\text { Each Factor Alone }\end{array}$ & $\begin{array}{c}\text { Increase in Explanatory } \\
\text { Power from Adding Each } \\
\text { Factor to All the Others }\end{array}$ \\
\hline Inflation & $1.3 \%$ & $0.0 \%$ \\
Term structure & 1.1 & 7.7 \\
Industrial production & 0.5 & 0.3 \\
Default premium & 2.4 & 8.1 \\
Unemployment & -0.3 & 0.1 \\
All five factors & & 10.9 \\
\hline
\end{tabular}


Table 4. The Explanatory Power of the Fundamental Factors

\begin{tabular}{lcc}
\hline Factor & $\begin{array}{c}\text { Explanatory Power from Using } \\
\text { Each Factor Alone }\end{array}$ & $\begin{array}{c}\text { Increase in Explanatory } \\
\text { Power from Adding Each } \\
\text { Factor to All the Others }\end{array}$ \\
\hline Industries & $16.3 \%$ & $18.0 \%$ \\
Variability in markets & 4.3 & 0.9 \\
Success & 2.8 & 0.8 \\
Size & 1.4 & 0.6 \\
Trade activity & 1.4 & 0.5 \\
Growth & 3.0 & 0.4 \\
Earnings to price & 2.2 & 0.6 \\
Book to price & 1.5 & 0.6 \\
Earnings variability & 2.5 & 0.4 \\
Financial leverage & 0.9 & 0.5 \\
Foreign investment & 0.7 & 0.4 \\
Labor intensity & 2.2 & 0.5 \\
Dividend yield & 2.9 & 0.4 \\
All factors & & 42.6 \\
\hline
\end{tabular}

indexes. ${ }^{9}$ The industry dummies are added to the model together as a single set of factors rather than one at a time. Otherwise, the table has the same form as Table 3 . Note the high explanatory power of the industry dummies. ${ }^{10}$

The statistic from Connor and Korajczyk also has a natural application to comparisons across the three types of factor models. For example, the test can be used to determine whether a five-factor statistical factor model explains all of the pervasive comovements in returns against the alternative that a set of macroeconomic factors has pervasive explanatory power not captured by the statistical factors. All of the macroeconomic factors are added simultaneously as a set of pseudofactors. The difference in cross-sectional average assetspecific variance before and after the set of macroeconomic factors is added to the statistical factor model gives the test statistic.

This same procedure can be applied symmetrically to each of the models compared with any other one. Comparing three models, one of each type, with one another requires six tests-each of the three models tested against the other two. The matrix in Table 5 shows the results. The first row, drawing upon Tables 2 through 4 , shows the explanatory power of each factor model considered separately. The next three rows show the additional explanatory power attained by combining any two types of factor models. The column headings are the first models estimated, and the row headings are the second. This table contains much of interest, but I will note only two findings. First, the fundamental factor model slightly outperforms the statistical factor model. How can this happen when the statistical factor model is estimated by maximizing explanatory power? The answer lies in the much larger number of explanatory variables that can be used in a fundamental factor model (especially the industry dummies). Of course, using more explanatory variables requires a large amount of external data, whereas the statistical factor model only requires returns data. The much larger data set used by the fundamental factor model compensates for the fact that the statistical factor model is estimated by maximizing explanatory power.

Another interesting finding is that the macroeconomic factor model has no marginal explanatory power when added to the fundamental factor

Table 5. The Marginal Explanatory Power of Each Type of Factor Model

\begin{tabular}{lccc}
\hline & \multicolumn{3}{c}{ First Model } \\
\cline { 2 - 4 } Second Model & Macroeconomic & Statistical & Fundamental \\
\hline Total explanatory power & $10.9 \%$ & $39.0 \%$ & $42.6 \%$ \\
Macroeconomic & - & 38.2 & 42.4 \\
Statistical & 31.0 & - & 44.8 \\
Fundamental & 43.0 & 45.6 & - \\
\hline
\end{tabular}


model. This result implies that the risk attributes in the fundamental factor model capture all the risk characteristics captured by the macroeconomic factor betas. It is not clear (and is left as a problem for future research) how to rotate the fundamental risk attributes to equate some combination of them to the macroeconomic factor betas. ${ }^{11}$ This future research might provide insight on how corporate characteristics or industry categories are related to return sensitivity to various macroeconomic shocks. The statistical factor model also eliminates all of the explanatory power of the macroeconomic factor model, but this result is less useful than that for the fundamental factors because the statistical factors have no theoretical content.

\section{CONCLUSION}

We have compared the explanatory power of the three types of factor models typically applied to security market returns. A particular specification of each of the three types of models was estimated, and the total and marginal explanatory power of each was examined. The statistical and fundamental factor models substantially outperform the macroeconomic factor model. The fundamental factor model slightly outperforms the statistical factor model.

The comparison of explanatory power is only one criterion by which to evaluate the relative worth of the three approaches to factor modeling. By other important criteria such as theoretical consistency and intuitive appeal, using a macroeconomic factor model is probably the strongest (rather than the weakest) of the three approaches. Thus, our results, although interesting and useful, are not the final word in choosing among the three approaches. ${ }^{12}$

\section{FOOTNOTES}

1. The seminal reference for macroeconomic factor models is N.F. Chen, R. Roll, and S.A. Ross, "Economic Forces and the Stock Market," The Journal of Business, vol. 59, no. 3 (July 1986):383-404. The Chen, Roll, and Ross model has been extended and refined by, among others, M.A. Berry, E. Burmeister, and M.B. McElroy, "Sorting Out Risks Using Known APT Factors," Financial Analysts Journal, vol. 44, no. 2 (March/April 1988):29-42; and K.C. Chan, N.F. Chen, and D. Hsieh, "An Exploratory Investigation of the Firm Size Effect," Journal of Financial Economics, vol. 14, no. 3 (September 1985):451-71.

2. Examples of this type of factor model include B.A. Rosenberg, "Extra-Market Components of Covariance in Security Returns," Journal of Financial and Quantitative Analysis, vol. 9, no. 2 (March 1974):263-73; S. Beckers, R. Grinold, A. Rudd, and D. Stefek, "The Relative Importance of Common Factors across the European Equity Markets," Journal of Banking and Finance, vol. 16, no. 1 (March 1992): 75-96; and R. Grinold and R.N. Kahn, "Multiple-Factor Models of Portfolio Risk," in A Practitioners Guide to Factor Models (Charlottesville, Va.: The Research Foundation of the Institute of Chartered Financial Analysts, 1994): 59-78.

3. See B. Lehman and D.A. Modest, "The Empirical Foundations of the Arbitrage Pricing Theory," Journal of Financial Economics, vol. 21, no. 2 (September 1988):213-54.

4. G. Connor and R.A. Korajczyk, "A Test for the Number of Factors in an Approximate Factor Model," The Journal of Finance, vol. 48, no. 4 (September 1993):1263-92.

5. The cross-sectional sample consists of all securities in the BARRA high-capitalization universe of U.S. equities that had complete histories of monthly returns over the sample time period.

6. See Connor and Korajczyk, "A Test for the Number of Factors," Table I, p. 1277.

7. The inflation factor is the change in the natural log of the consumer price index, the term structure factor is the difference between the return on a long-term government bond index and the one-month Treasury bill return, the industrial production factor is the change in the natural log of the industrial production index, the default premium factor (the junk-bond premium) is the difference between the return on a high-yield bond index and a long-term government bond index, and the unemployment factor is the change in the unemployment rate.

8. All variance estimates are corrected for regression degrees of freedom, so the marginal contribution of a variable can be zero or negative.

9. For detailed descriptions of the industry categories and risk indexes, see The United States Equity Model Handbook (Berkeley, Ca.: BARRA Inc., 1994).

10. J.K. Kale, N.H. Hakansson, and W.G. Platt, in "Industry Factors versus Other Factors in Risk Prediction," working paper, University of California, Berkeley, 1991, also found that the industry attributes are the most powerful component of a fundamental factor model.

11. A recent paper by E.F. Fama and K.R. French, "Common Risk Factors in the Returns of Stocks and Bonds, "Journal of Financial Economics, vol. 33, no. 1 (February 1993):3-56, uses a mixed approach that combines elements of macroeconomic and fundamental factor models.

12. I would like to thank Ian Buckley and Marielle DeJong for research assistance. 
Copyright of Financial Analysts Journal is the property of CFA Institute. The copyright in an individual article may be maintained by the author in certain cases. Content may not be copied or emailed to multiple sites or posted to a listserv without the copyright holder's express written permission. However, users may print, download, or email articles for individual use. 